\title{
The electrochemical synthesis of polypyrrole at a copper electrode: corrosion protection properties
}

\author{
Anna M. Fenelon, Carmel B. Breslin ${ }^{1, *}$ \\ Department of Chemistry, National University of Ireland Maynooth, Maynooth, Co. Kildare, Ireland
}

Received 17 June 2002; received in revised form 7 August 2002; accepted 7 August 2002

\begin{abstract}
Pyrrole was successfully electropolymerized at a copper electrode in a near neutral sodium oxalate solution to generate a homogeneous and adherent polypyrrole film. The growth of these films was facilitated by the initial oxidation of the copper electrode in the oxalate solution to generate a copper oxalate pseudo-passive layer. This layer was sufficiently protective to inhibit further dissolution of the copper electrode and sufficiently conductive to enable the electropolymerization of pyrrole at the interface, and the generation of an adherent polypyrrole film. These films remained stable and conducting for periods exceeding eight days and exhibited significant corrosion protection properties in acidified and neutral $0.1 \mathrm{~mol} \mathrm{dm}^{-3} \mathrm{NaCl}$ solutions even on polarization to high anodic potentials. (C) 2002 Elsevier Science Ltd. All rights reserved.
\end{abstract}

Keywords: Polypyrrole; Copper; Corrosion; Oxalate; Passive

\section{Introduction}

The initiation and the propagation of corrosion on pure copper is a major concern in technologies ranging from microelectronics to electrostatic dissipation. Consequently, there is an ever-increasing interest in formulating new corrosion-control measures that will inhibit or diminish the corrosion of pure copper and its alloys.

Possibly the best known, and one of the more studied, corrosion protection strategies involves the use of benzotriazole, a heterocyclic compound. The mode of action of this inhibitor has been attributed to the formation of a polymeric-type film comprising $\mathrm{Cu}(\mathrm{I})-$ BTA units, with the highest degree of corrosion protection being afforded by a thin polymerized film formed on an oxidized $\mathrm{Cu}$ surface [1-4]. Although benzotriazole is an excellent inhibitor suitable for use in a wide variety of environments, it is toxic. Consequently, much of the recent research has concentrated on formulating new \footnotetext{
3815

* Corresponding author. Tel.: +353-1-708-3770; fax: +353-1-708-

E-mail address: cb.breslin@may.ie (C.B. Breslin).

${ }^{1}$ ISE Member.
}

and more environmentally acceptable polymeric-type coatings. For example, Cicileo et al. [5] have shown that oxime compounds, such as benzoinoxime and salycilaldoxime lead to the formation of a polymeric $\mathrm{Cu}(\mathrm{II})-$ inhibitor complex that exhibits strong corrosion inhibition. Guenbour et al. [6] have studied the corrosion protection of copper by polyaminophenol films obtained through the electropolymerization of the monomer, 2-aminophenol, in alkaline hydroalcoholic solution. There have also been reports on the formation of polymeric films through the electrochemical oxidation of 3-amino 1,2,4-triazole [7,8], self assembled monolayers of alkanethiol [9,10], alkanethiol monolayers modified with tetrachlorosilane, 1,2-bis(trichlorosilyl)ethane, 1,8-octanediol, and/or octyltrichlorosilane [11] and insulating polymers fabricated by oxidizing 2-mercaptobenzimidazole in alkaline water-methanol solutions [12].

Although there is an extensive literature on the corrosion protection properties of conducting polymers, such as polyaniline and polypyrrole on iron or ironbased alloys [13-15] there are very few reports devoted to the corrosion protection properties of these polymers when applied to copper or copper-based alloys. In the cases where these polymers have been considered, they have first been synthesized chemically, and then depos- 
ited at the metal surface, for example by spin coating [16]. Brusic et al. [16] have studied the corrosion protection properties of polyaniline and its derivatives when spin-coated onto copper as a function of the applied potential and temperature. It was found that polyaniline could either enhance the corrosion rate or produce significant corrosion protection properties depending on the chemical nature of the polymer backbone and on the oxidation state and extent and nature of polymer doping.

In this paper results are presented on the in-situ electropolymerization of pyrrole at a copper electrode from a near-neutral oxalate solution to produce an adherent polypyrrole coating. The corrosion protection properties of this layer are assessed using electrochemical techniques. To the best of our knowledge there are no reports in the literature concerning the electropolymerization of pyrrole at a copper surface to generate an adherent polypyrrole layer with corrosion protection properties.

\section{Experimental}

Electrodes were prepared from pure copper $(99.99+$ $\%)$. The electrodes were provided in rod form $(5 \mathrm{~mm}$ in diameter) and as sheets. The sheet samples were used for surface analyses only, while the rod samples were used in all electrochemical measurements. These rods were embedded in epoxy resin in a Teflon holder with electrical contact being achieved by means of a copper wire threaded into the base of the metal sample. Prior to each test the exposed surfaces were polished to a smooth surface finish, using $1200 \mathrm{~g} \mathrm{SiC}$, and rinsed with distilled water. High-density graphite rods were used as the auxiliary electrodes and a saturated calomel electrode (SCE) was used as the reference electrode, with all potentials represented relative to this electrode. The electrolytes were prepared using analytical grade reagents and distilled water.

The electropolymerization solution consisted of 0.1 mol dm ${ }^{-3}$ pyrrole added to a $0.125 \mathrm{~mol} \mathrm{dm}^{-3}$ sodium oxalate solution, $\mathrm{pH}$ of 7.6. A $0.1 \mathrm{~mol} \mathrm{dm}^{-3} \mathrm{NaCl}$ solution, adjusted to $\mathrm{pH}$ values between 3.5 and 7.8, using either $\mathrm{NaOH}$ or $\mathrm{HCl}$ was used as the aggressive solution.

Electrochemical experiments were carried out using an EG\&G Potentiostat, Model 263, a Solartron 1250 frequency response analyser and a Solartron EI 1287 electrochemical interface. The polymers were formed using cyclic voltammetry or at a constant potential, typically between 800 and $1000 \mathrm{mV}$ (SCE). Once formed, the electrochemical and corrosion-protection properties of the polymer-modified electrodes were assessed. The electrochemical tests consisted of cyclic voltammetry, while the corrosion tests involved anodic polarization measurements and electrochemical impedance tests. Cyclic voltammograms were recorded in the monomer-free oxalate solution at $20 \mathrm{mV} \mathrm{s}^{-1}$ from an initial potential of $-500 \mathrm{mV}$ (SCE) up to a vertex potential of $1000 \mathrm{mV}$ (SCE). Anodic polarization tests were recorded in the chloride-containing solutions from below the corrosion potential, at a scan rate of $0.5 \mathrm{mV}$ $\mathrm{s}^{-1}$ in the anodic direction, until breakdown occurred. Electrochemical impedance measurements were recorded at the corrosion potential following different immersion periods under open-circuit conditions. An excitation voltage of $10 \mathrm{mV}$ was used in all tests. The frequency of the potential perturbation was varied between $65 \mathrm{kHz}$ and $2 \mathrm{mHz}$. All impedance data were fit to appropriate equivalent circuits using a complex non-linear least squares fitting routine, using both the real and imaginary components.

Scanning electron micrographs and energy dispersive $\mathrm{x}$-ray analyses were recorded on a Hitachi S-4700 cold cathode field emission SEM using a secondary electron detector at an accelerating voltage of $15 \mathrm{kV}$. The samples were gold coated prior to imaging using an Emitech K550 sputter coater.

\section{Results}

The electrosynthesis of polypyrrole at copper was attempted using aniline, various acids or inorganic salts all adjusted to different concentrations. In the case of the inorganic salts these were adjusted, also, to different $\mathrm{pH}$ values. The acids used included oxalic, tosylic, phosphoric and sulphuric acid, while the inorganic salts comprised sulphates, nitrates and oxalates, adjusted to $\mathrm{pH}$ values between 6.0 and 8.0. All attempts at polymerizing the monomer to generate a conducting polymer in an acidic medium, at the copper electrode, failed as these high acidic conditions promote dissolution of copper before growth of the polymer can be achieved. Likewise, dissolution of copper occurred in the sulphate and nitrate solutions inhibiting the formation of the polymer. However, the copper electrodes were passivated, partially, in a near-neutral oxalate solution, enabling electropolymerization of pyrrole and the growth of an adherent and homogenous polypyrrole film.

The electrochemical behaviour of copper in this neutral oxalate solution in the absence and presence of pyrrole is shown in Figs. 1 and 2 respectively. In Fig. 1, a voltammogram, recorded in the pyrrole-free solution, showing the forward and reverse scans of the first cycle, is presented. Dissolution of copper begins at $-180 \mathrm{mV}$ (SCE), a peak is seen at $-40 \mathrm{mV}$ (SCE) which is consistent with the formation of $\mathrm{Cu}(\mathrm{I})$ oxide. On polarising further in the anodic direction, more intense dissolution is seen with current peaks being observed at 


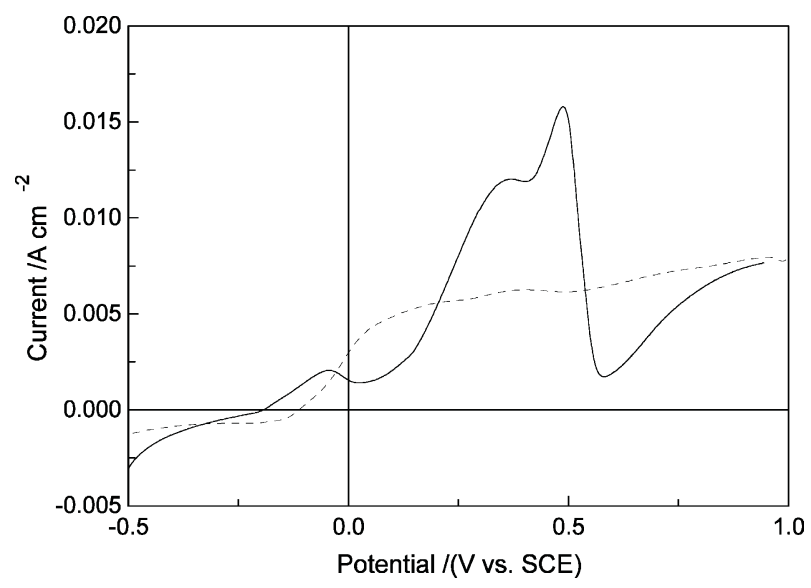

Fig. 1. Cyclic voltammograms recorded for pure copper in a $0.125 \mathrm{~mol}$ $\mathrm{dm}^{-3} \mathrm{Na}_{2} \mathrm{C}_{2} \mathrm{O}_{4}, \mathrm{pH} 7.8$ solution, - (forward scan),---(reverse scan).

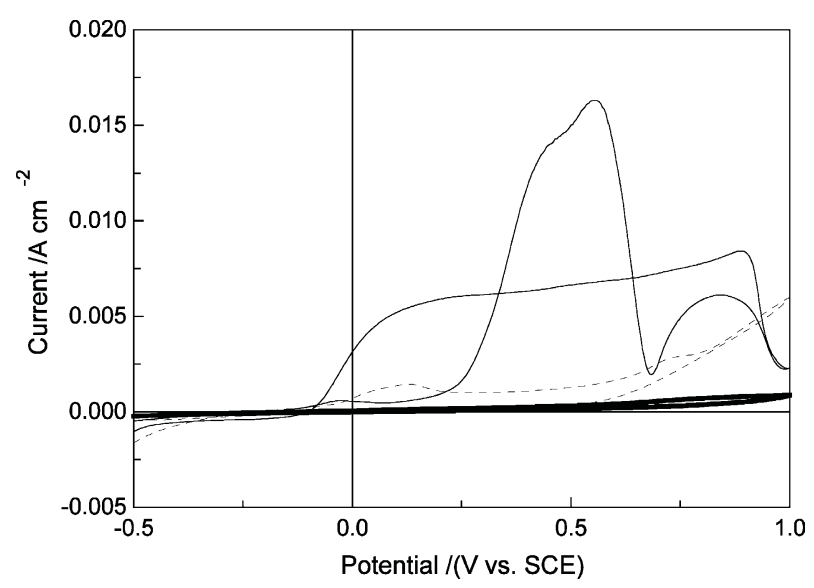

Fig. 2. Cyclic voltammograms recorded for copper in a $0.1 \mathrm{~mol} \mathrm{dm}^{-3}$ pyrrole solution in $0.125 \mathrm{~mol} \mathrm{dm}^{-3} \mathrm{Na}_{2} \mathrm{C}_{2} \mathrm{O}_{4}, \mathrm{pH} 7.8$ solution, second cyle,---6th cycle and $\cdots 1$ th cycle.

360 and $490 \mathrm{mV}$ (SCE). These appear to be connected with the formation of $\mathrm{Cu}$ (II) oxalates, with the likely oxalates being $\mathrm{Cu}(\mathrm{Ox})$ and $\left(\mathrm{Cu}(\mathrm{Ox})_{2}\right)^{2-}$, where $\mathrm{Ox}$ represents the oxalate species [17]. The current increases again on polarization to potentials in the region of 1000 $\mathrm{mV}$ (SCE). On reversing the potential the current remains high indicating that the dissolution initiated at the high potentials, $1000 \mathrm{mV}$ (SCE), during the forward scan continues until the potential is reduced to low values in the region of $0 \mathrm{~V}$ (SCE). Although the electrochemical behaviour of copper in this medium is highly complex with the formation of copper oxalate species, it was possible to form adherent polypyrrole layers on the copper electrode by adding pyrrole to this oxalate solution, in sharp contrast to that observed with the other salt and acid solutions.

The voltammograms recorded on polarising copper in the pyrrole-containing oxalate solution are shown in Fig. 2. Here, three voltammograms are shown; the second, sixth and tenth cycles. It can be seen on comparing these plots that the second cycle is similar to that presented in Fig. 1, consistent with the dissolution of copper and the formation of copper oxalate species. However, on subsequent cycling the behaviour changes as the polypyrrole coating is nucleated at the copper surface. The oxalate peaks are no longer visible in the sixth cycle. There is some evidence of dissolution at the high potentials, but on polarising further, dissolution at these high potentials is inhibited. Low currents are recorded at all potentials in the tenth cycle indicating that the deposited polypyrrole coating is inhibiting dissolution of the substrate copper in the oxalate solution.

It was also possible to form homogenous and adherent polypyrrole coatings on copper in this pyrrole-containing solution at constant applied potentials higher than $700 \mathrm{mV}$. In these experiments, the nature of the copper surface was critical to the subsequent rate of polymer growth. In fact, a high degree of reproducibility was only obtained when the electrode was reduced at $400 \mathrm{mV}$ in the absence of pyrrole for $5 \mathrm{~min}$ and then subjected to the formation potential in the presence of pyrrole. Typical current-time responses are shown in Fig. 3(a). Three sets of data are presented; data from a single experiment recorded in $0.1 \mathrm{~mol} \mathrm{dm}^{-3}$ pyrrole, data from two separate experiments recorded in $0.2 \mathrm{~mol}$ $\mathrm{dm}^{-3}$ pyrrole and data from a single experiment recorded in $0.3 \mathrm{~mol} \mathrm{dm}^{-3}$ pyrrole. The high degree of reproducibility can be seen from the two profiles recorded in $0.2 \mathrm{~mol} \mathrm{dm}^{-3}$ pyrrole, and although not shown here the electrochemical response on forming polypyrrole at the other concentrations was also highly reproducible. The current-time transients are characterised by an initial rapid decrease in current and then a slight increase in current, as the copper oxalate species are formed. This is then followed by a more gradual decrease or an increase in current as the polypyrrole is nucleated and grows at the copper interface. Much higher rates of polypyrrole formation can be seen with the higher concentrations of pyrrole, as expected. The formation of the copper-oxalate passive layer can be seen more clearly in Fig. 3(b), where the current-time data are presented for polarization of copper in the monomer-free solution. The current decays rapidly for the first $1.75 \mathrm{~s}$, but then increases to reach a maximum at $5 \mathrm{~s}$, before decaying further. This is consistent with the initial dissolution of copper and the formation of a copper-oxalate passive layer.

In Fig. 3(c) a plot showing the total charge passed following the 30 -min polarisation period as a function of the pyrrole concentration is presented. It is clear that the charge passed is proportional to the concentration of the monomer in solution. However, this charge is not due completely to polymer growth. The horizontal line depicted on this plot corresponds to the total charge passed for the copper electrode polarised in the pyrrolefree solution. In fact, the charge passed in the $0.1 \mathrm{~mol}$ 

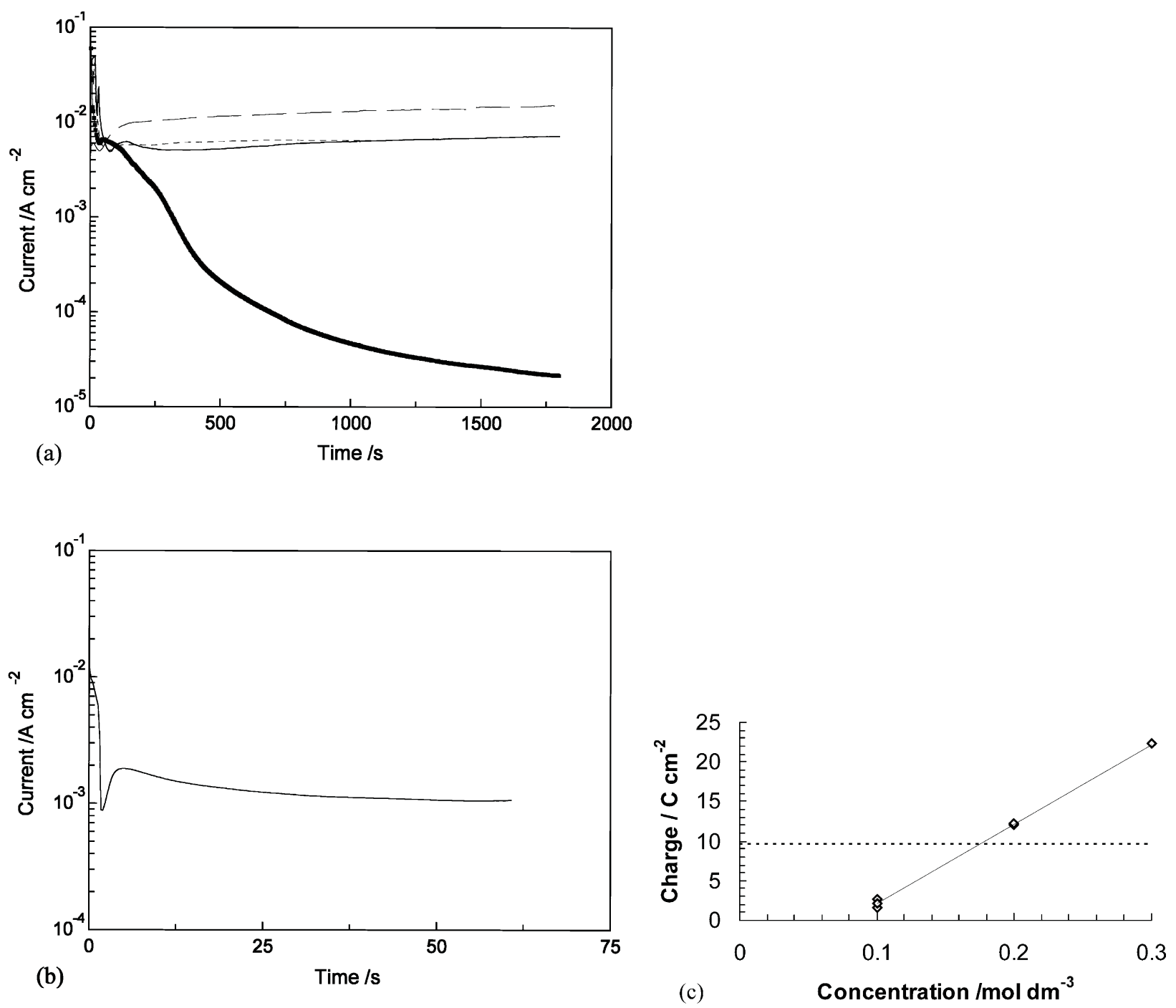

Fig. 3. (a) Potentiostatic current-time plots for $\mathrm{Cu}$ polarized at $0.9 \mathrm{~V}$ (SCE) in a pH $7.8,0.125 \mathrm{~mol} \mathrm{dm}^{-3} \mathrm{Na}_{2} \mathrm{C}_{2} \mathrm{O}_{4}$ solution containing pyrrole concentrations of $\cdots 0.1 \mathrm{~mol} \mathrm{dm}^{-3},-0.2 \mathrm{~mol} \mathrm{dm}^{-3},---0.2 \mathrm{~mol} \mathrm{dm}^{-3}$ and $---0.3 \mathrm{~mol} \mathrm{dm}^{-3}$. (b) Potentiostatic current-time plot recorded for $\mathrm{Cu}$ polarized at $0.9 \mathrm{~V}$ (SCE) in a pH 7.8, $0.125 \mathrm{~mol} \mathrm{dm}^{-3} \mathrm{Na}_{2} \mathrm{C}_{2} \mathrm{O}_{4}$ solution. (c) Charge passed during polymer growth as a function of the pyrrole concentration.

$\mathrm{dm}^{-3}$ pyrrole solution is lower than that in the absence of pyrrole indicating that the thin layer of polypyrrole deposited initially is capable of protecting the metal from dissolution in this solution. It can be seen from this plot that the total charge difference between the system formed in the 0.1 and $0.2 \mathrm{~mol} \mathrm{dm}^{-3}$ pyrrole-containing solution is $10 \mathrm{C} \mathrm{cm}^{-2}$. Using a film thickness of $10 \mu \mathrm{m}$ for a $6 \mathrm{C} \mathrm{cm}^{-2}$ charge [18] this corresponds to a difference in the film thickness between both systems of approximately $15-16 \mu \mathrm{m}$.

Typical SEM micrographs showing the morphology of the polypyrrole coating on the copper substrate, formed from a $0.2 \mathrm{~mol} \mathrm{dm}^{-3}$ pyrrole solution, is shown in Fig. 4. The micrographs presented show the surface at different magnifications. These data were recorded following dehydration of the polymer. The polymers were formed and then exposed to the atmosphere at
$25{ }^{\circ} \mathrm{C}$ for 7 days. The data in Fig. 4(a) show clearly that the polymer is homogenous and is crack and defect-free despite being relatively thick and dehydrated over an extended period, which indicates that the metal-polymer arrangement is stable. The micrograph shown in Fig. 4(b) shows the characteristic microspheroidal grains or aggregates of polypyrrole, with sizes up to $2 \mu \mathrm{m}$. It is also interesting to note that the deposition of the polypyrrole appears to take place along polishing lines on the copper surface, as evident from the ridge-like diagonal trace in Fig. 4(b).

In Fig. 5(a) and (b), the electrochemical behaviour of the polypyrrole-coated copper electrode, formed in the $0.1 \mathrm{~mol} \mathrm{dm}^{-3}$ pyrrole solution, and pure copper are compared in the monomer-free solution. In these plots, cyclic voltammograms are presented showing the first, second, third and fourth cycles, recorded at $20 \mathrm{mV} \mathrm{s}^{-1}$. 




(a)

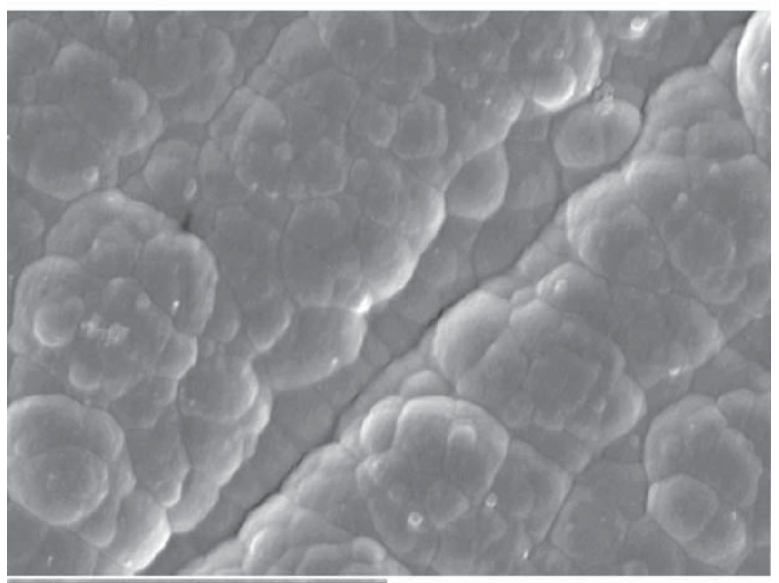

$5.0 \mu \mathrm{m}$

(b)

Fig. 4. SEM micrographs of polypyrrole-coated copper (a) under low magnification and (b) under high magnification.

The data presented for the polypyrrole-coated $\mathrm{Cu}$ electrode are characteristic of polypyrrole; the currents increase slightly on cycling, nevertheless there is no evidence of any degradation as a result of polarization to the extreme values of -500 and $1000 \mathrm{mV}$ (SCE). However, data recorded under similar conditions for the pure copper electrode are very different. The first cycle is similar to that shown in Fig. 1, with the anodic current in the forward direction being associated with dissolution of the copper and the formation of copper-oxalate species. Nevertheless, the potential at which these reactions occur increases in the anodic direction with increasing cycle, which suggests some stabilization of the copper electrode as a result of the formation of copperoxalate corrosion products on the surface. However, the most significant factor is the difference between the polypyrrole-coated and uncoated electrode. The polypyrrole coating is sufficiently protective to inhibit dissolution of the copper substrate even at high potential values where oxidation of the polypyrrole occurs.
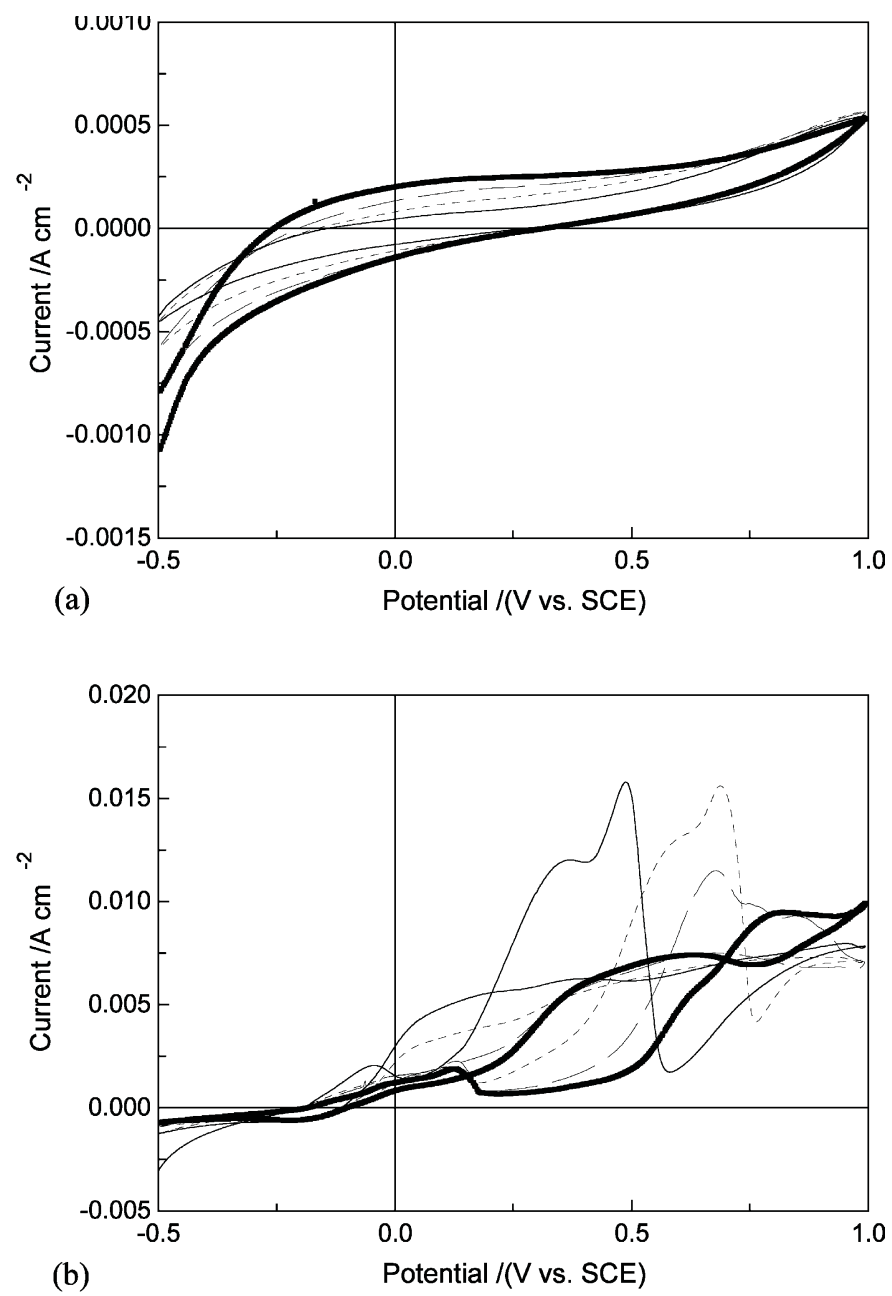

Fig. 5. (a) Cyclic voltammograms recorded for polypyrrole-coated copper in a $0.125 \mathrm{~mol} \mathrm{dm}{ }^{-3} \mathrm{Na}_{2} \mathrm{C}_{2} \mathrm{O}_{4}$, pH 7.8 solution, - 1 st cycle,--2nd cycle, ---3 rd cycle and $\cdots 4$ th cycle. (b) Cyclic voltammograms recorded for pure copper in a $0.125 \mathrm{~mol} \mathrm{dm}^{-3} \mathrm{Na}_{2} \mathrm{C}_{2} \mathrm{O}_{4}, \mathrm{pH} 7.8$ solution, - 1 st cycle,---2nd cycle, $--\quad-3$ rd cycle and $\cdots 4$ th cycle.

The corrosion-protection properties of the polypyrrole film are shown in Figs. 6-8. Anodic polarization data are presented in Fig. 6 for pure copper, copper coated with a 'thin' polypyrrole film (from $0.1 \mathrm{~mol}$ $\mathrm{dm}^{-3}$ pyrrole) and copper coated with a 'thick' poly-

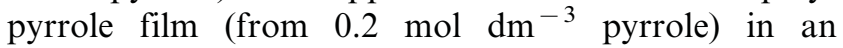
acidified, pH 3.0 chloride-containing solution, Fig. 6(a), and in a near-neutral chloride solution, Fig. 6(b). For comparative purposes, a polarization plot recorded for a polypyrrole-coated platinum electrode polarized in the acidic solution in shown also in Fig. 6(a). The plots depicted for pure copper are consistent with dissolution of copper, with corrosion potentials close to $-130 \mathrm{mV}$ (SCE) and high anodic currents, exceeding $1 \mathrm{~mA} \mathrm{~cm}^{-2}$, being observed at potentials higher than $-50 \mathrm{mV}$ (SCE). The anodic peak visible at potentials in the region of $0 \mathrm{~V}(\mathrm{SCE})$ is probably associated with the formation of copper-chloride complexes, such as $\mathrm{CuCl}$. The behaviour of the polymer-coated electrodes is significantly different. In the acidic solution, the corro- 

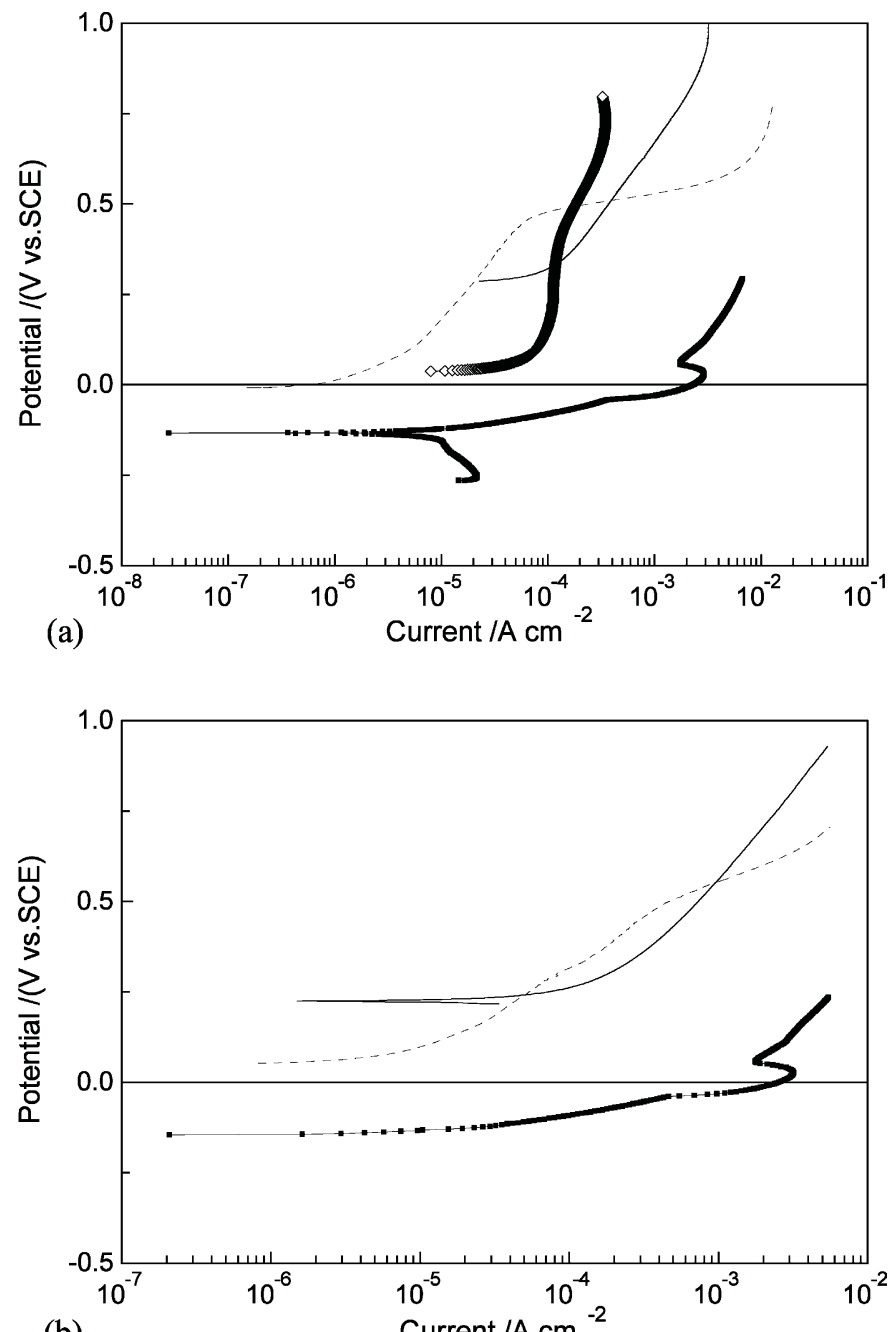

(b)

Current $/ \mathrm{A} \mathrm{cm}^{-2}$

Fig. 6. (a) Anodic polarization plots recorded in a $\mathrm{pH} 3.5,0.1 \mathrm{~mol}$ $\mathrm{dm}^{-3} \mathrm{NaCl}$ solution for $\cdots$ uncoated $\mathrm{Cu}$,---Cu coated with a 'thin' polypyrrole layer, $-\mathrm{Cu}$ coated with a 'thick' polypyrrole layer and $\diamond$ polypyrrole-coated platinum. (b) Anodic polarization plots recorded in a $\mathrm{pH} 7.8,0.1 \mathrm{~mol} \mathrm{dm}{ }^{-3} \mathrm{NaCl}$ solution for $\cdots$ uncoated $\mathrm{Cu},---\mathrm{Cu}$ coated with a 'thin' polypyrrole layer, and $-\mathrm{Cu}$ coated with a 'thick' polypyrrole layer.

sion potentials adopted by the 'thin' and 'thick' polymer films are 0 and $290 \mathrm{mV}$ (SCE), respectively. But, more significantly, the polymers remain protective at much higher potentials. A clear breakdown potential at 470 $\mathrm{mV}$ (SCE) can be seen for the 'thin' polymer, but the conducting properties of the 'thick' polymer make it difficult to mark the onset of copper dissolution as the current-potential response is governed mainly by the activity of the polypyrrole and not the copper substrate. The electroactivity of the polypyrrole film can be seen clearly by considering the data recorded for the polypyrrole-coated platinum electrode. It should be pointed out that these polypyrrole coatings deposited at platinum are somewhat 'thinner' than the 'thick' polypyrrole coatings deposited on copper. Nevertheless, it can be seen that the anodic currents recorded for the platinum
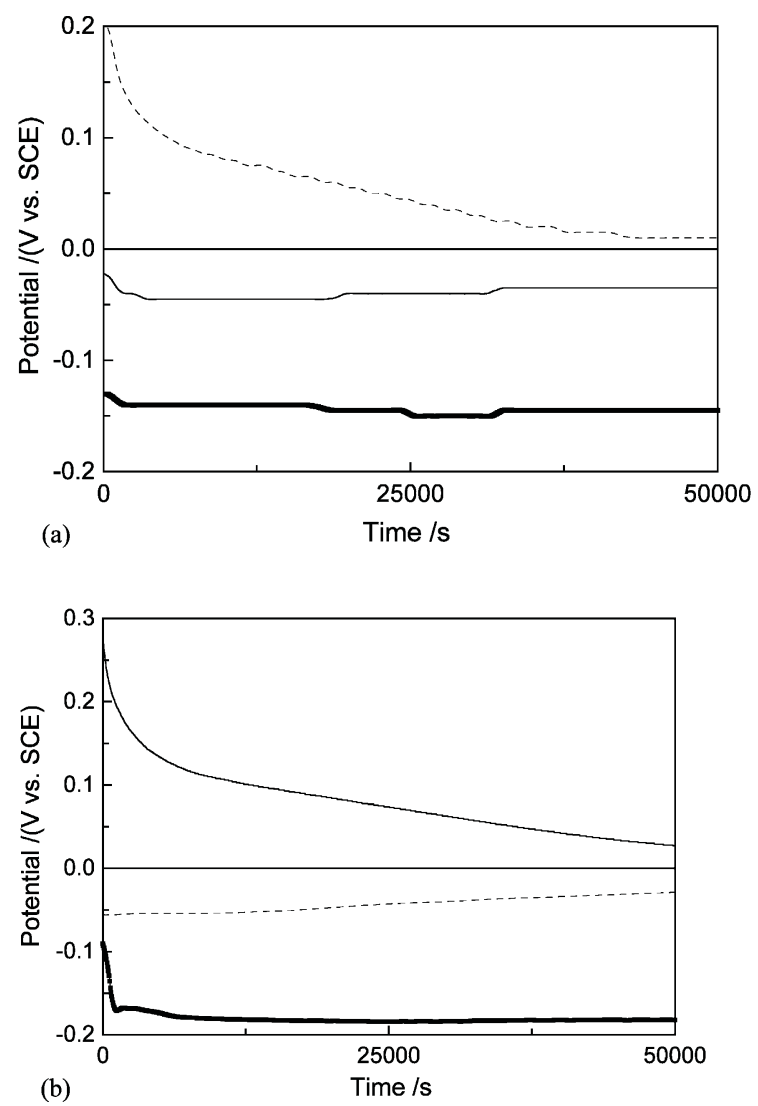

Fig. 7. (a) Open-circuit potential-time plots recorded in a pH 3.5, 0.1 mol $\mathrm{dm}^{-3} \mathrm{NaCl}$ solution for $\cdots$ uncoated $\mathrm{Cu},-\mathrm{Cu}$ coated with a 'thin' polypyrrole layer, and---Cu coated with a 'thick' polypyrrole layer. (b) Open-circuit potential-time plots recorded in a $\mathrm{pH} 7.8,0.1$ mol dm ${ }^{-3} \mathrm{NaCl}$ solution for $\cdots$ uncoated $\mathrm{Cu},---\mathrm{Cu}$ coated with a 'thin' polypyrrole layer, and - Cu coated with a 'thick' polypyrrole layer.

system are significantly higher than those recorded for the 'thin' coatings on copper and approach those recorded for the 'thick' polymer coatings on copper. The much lower rest potential recorded for the platinum system compared with that recorded for the 'thick' polypyrrole coating on copper is connected with the fact that the polypyrrole-coated platinum electrode was cycled in the oxalate solution down to $-0.5 \mathrm{~V}$ (SCE) prior to polarization in the aggressive chloride solution. This was to ensure that the polymer was doped with the oxalate species.

Similar corrosion-protection properties can be seen in the neutral solution, Fig. 6(b). The corrosion potentials of the polypyrrole-coated electrodes are significantly higher at $50 \mathrm{mV}$ (SCE) for the 'thin' polymer and $225 \mathrm{mV}$ (SCE) for the 'thick' polymer. Likewise the polymers exhibit good corrosion-protection properties on polarization in the anodic direction with breakdown of the 'thin' polypyrrole coating occurring at $500 \mathrm{mV}$ (SCE), while no clear evidence of breakdown can be seen with the 'thick' polymer. Again, the high currents measured for the 'thick' polymer appear to be associated with the conducting properties of the polymer and not 


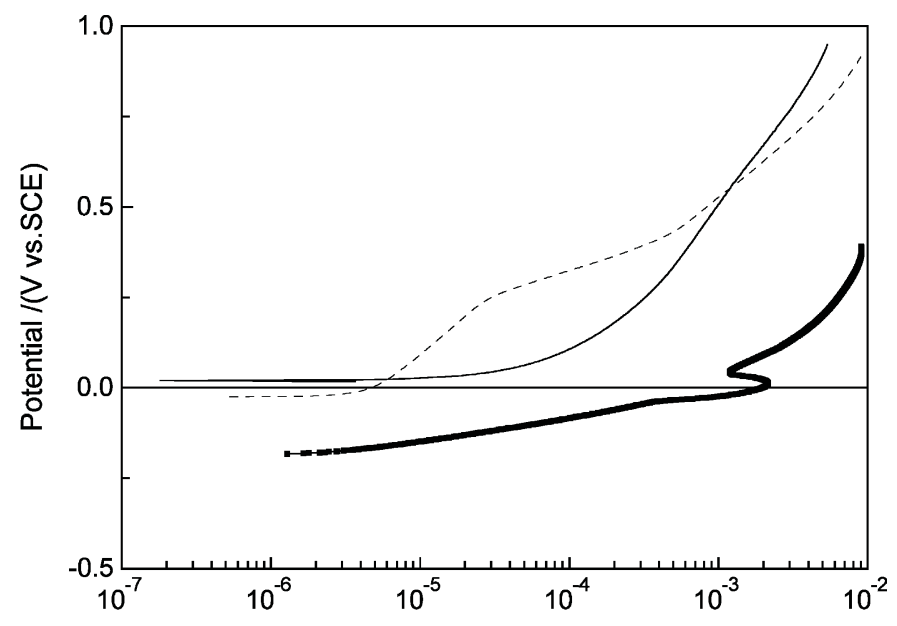

(a)

Current $/ \mathrm{A} \mathrm{cm}^{-2}$

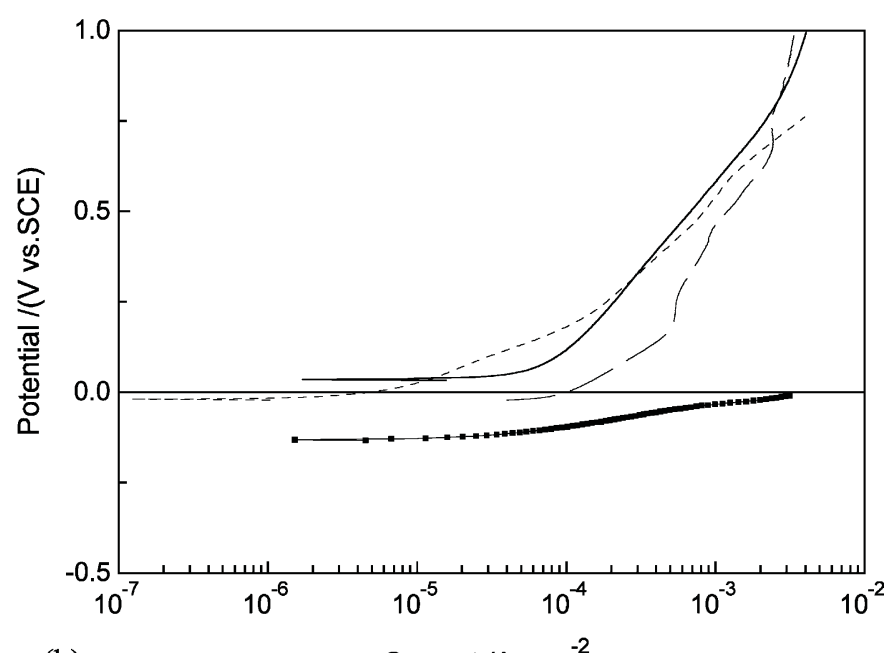

(b)

Current $/ \mathrm{A} \mathrm{cm}^{-2}$

Fig. 8. (a) Anodic polarization plots recorded in a $\mathrm{pH} 7.8,0.1 \mathrm{~mol}$ $\mathrm{dm}^{-3} \mathrm{NaCl}$ solution following $14 \mathrm{~h}$ immersion for $\cdots$ uncoated $\mathrm{Cu}$,--$\mathrm{Cu}$ coated with a 'thin' polypyrrole layer, and $-\mathrm{Cu}$ coated with a 'thick' polypyrrole layer. (b) Anodic polarization plots recorded in a $\mathrm{pH} 3.5,0.1 \mathrm{~mol} \mathrm{dm}^{-3} \mathrm{NaCl}$ solution following $14 \mathrm{~h}$ immersion for $\cdots$ uncoated $\mathrm{Cu}$,---Cu coated with a 'thin' polypyrrole layer, $-\mathrm{Cu}$ coated with a 'thick' polypyrrole layer and - - - polypyrrole coated $\mathrm{Cu}$ following 8 days immersion.

dissolution of the underlying copper substrate. Further evidence in support of this was obtained by adding a copper-sensitive indicator, Murexide, to the test solution and monitoring any colour change at the polymer/ solution interface. This indicator which is violet in the absence of $\mathrm{Cu}^{2+}$, but changes to orange on complexation with $\mathrm{Cu}^{2+}$, remained violet in colouration even at potentials as high as $1.0 \mathrm{~V}$ (SCE) for the 'thick' polymer, indicating the absence of any substantial amount of $\mathrm{Cu}^{2+}$ at the polymer | solution interface. Also, voltammograms recorded following polarization to this high potential, were identical to those shown in Fig. 5(a), which again suggests the absence of large amounts of
$\mathrm{Cu}^{2+}$ trapped within the polymer. Thus, these 'thick' polymers appear to have excellent corrosion protection properties even when polarized to exceedingly high potentials.

The evolution of the corrosion, or open-circuit, potentials as a function of time can be seen in Fig. 7(a) and (b) for the polymer-modified electrodes immersed in the acidified and neutral chloride solutions, respectively. The open-circuit potential of the uncoated copper electrode remains constant, independent of time at a value of approximately $-140 \mathrm{mV}$ (SCE) in the acidified solution and $-180 \mathrm{mV}$ (SCE) in the near neutral solution. The open-circuit potentials of the polypyrrole-coated electrodes are significantly higher in both the acidified and neutral solutions. For example, in the acidic solution the open-circuit potential of the polymer-coated electrodes reaches values of approximately $200 \mathrm{mV}$ in the early stages of immersion and then decays to reach values close to $0 \mathrm{~V}$ (SCE) after a 14-h immersion period for the 'thick' polymers and extends between 0 and $-40 \mathrm{mV}$ (SCE) for the 'thin' polymers.

Although, the open-circuit potentials decay as a function of time, there is no indication of any substantial loss in the corrosion protection properties of the polypyrrole coatings. This can be seen clearly from the polarization data presented in Fig. 8(a) and (b), where the anodic polarization plots recorded following a 14-h immersion period in the neutral and acidified chloride solutions are shown, respectively. The data presented in Fig. 8(a), which were recorded in the neutral solution, show that the 'thin' and 'thick' polymer films can be polarised to relatively high potentials without any onset of copper dissolution. Again, there is no clear breakdown potential evident for the 'thick' coating, while, the onset of breakdown for the sample coated with the 'thin' polymer occurs at $250 \mathrm{mV}$ (SCE). This is somewhat lower than that observed on initial polarization, Fig. 6, but is still substantially higher than that observed for the uncoated electrode. Similar behaviour following the 14$\mathrm{h}$ immersion period is seen in the acidic solution. Included on this plot are the polarization data recorded for the 'thin' polymer following 8 days of immersion in the acidified solution. These data are interesting because they show that the corrosion potential of the polypyrrole-coated electrodes does not fall below the value reached after $14 \mathrm{~h}$ of immersion, but more importantly, the corrosion-protection properties are retained even after 8 days of immersion. Although, the anodic currents are somewhat higher for this system, the electrode can be polarized to potentials of $500 \mathrm{mV}$ (SCE) before the anodic current reaches $1 \mathrm{~mA} \mathrm{~cm}^{-2}$, which is reached by the uncoated electrodes at $-20 \mathrm{mV}$ (SCE).

In Fig. 9(a) and (b) electrochemical impedance data, recorded under open-circuit conditions in the acidic chloride-containing solution following an 800-min im- 

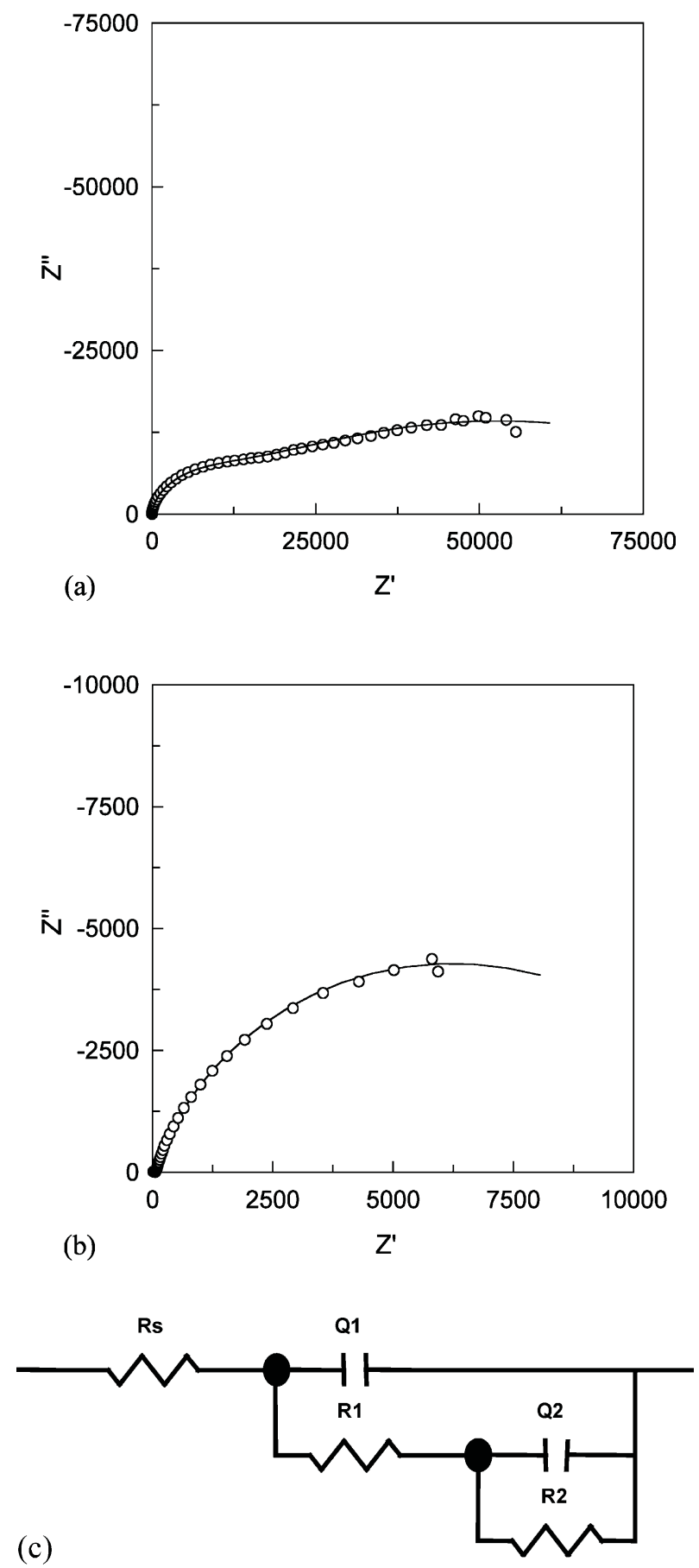

Fig. 9. Electrochemical impedance data recorded for (a) uncoated copper and (b) polypyrrole-coated copper in a $\mathrm{pH} 3.5,0.1 \mathrm{~mol} \mathrm{dm}^{-3}$ $\mathrm{NaCl}$ solution following $800 \mathrm{~min}$ (c) equivalent circuit used to fit impedance data.

mersion period, are presented for the uncoated and polypyrrole-coated copper electrodes. These data are presented as Nyquist plots with the experimental data represented by the symbols, while the continuous traces represent the simulated data, which is obtained using the equivalent circuit depicted in Fig. 9(c). This equivalent circuit represents a two-time constant model, with $R$ referring to resistance elements and $Q$ to constant phase elements. Although there is very good agreement between the experimental and simulated data generated using the same equivalent circuit, there is a considerable difference between the coated and uncoated electrodes. The impedance response of the uncoated copper electrode is characteristic of a system undergoing corrosion or dissolution with the precipitation of a corrosion film at the interface. In this case, $R_{1}$ represents the resistance of the copper-chloride corrosion film while $R_{2}$ represents the polarization resistance. The evolution of these terms as a function of time can be seen in Fig. 10. Both resistance values remain essentially independent of time, with $R_{1}$ adopting values in the region of $6 \times 10^{3} \Omega \mathrm{cm}^{2}$ and $R_{2}$ adopting values close to $8 \times 10^{4} \Omega \mathrm{cm}^{2}$. The impedance of the constant-phase element, $Q_{1}$, is defined as $Z_{\mathrm{CPE}}=\left[Q_{\mathrm{cf}}(j \omega)^{n}\right]^{-1}$ where $-1 \leq n \leq 1$. In this case, the $\mathrm{n}$ value was close to 1.0 , indicating that this is a near ideal capacitor and represents the capacitance associated with the double layer. These $Q_{1}$ values remain relatively constant at $5 \mu \mathrm{F} \mathrm{cm} \mathrm{cm}^{-2}$, typical of double layer capacitance values. $Q_{2}$, with an $n$ value close to 0.5 , represents a Warburg diffusional term. This is consistent with the fact that the chloride corrosion product layers are somewhat porous allowing diffusion to the underlying substrate.

It can be seen in Fig. 9(b) that the impedance of the polypyrrole-coated copper electrodes are dominated by the conducting properties of the polypyrrole. The $R_{1}$ term, which represents the resistance of the polymer film, is considerably lower than that of the copperchloride corrosion products. These $R_{1}$ values for the polypyrrole-coated copper electrodes remain relatively independent of time as shown in Fig. 10, reaching values close to $60 \Omega \mathrm{cm}^{2} . R_{1}$ represents the ionic and electronic resistance of the polymer film. These resistance terms have been analysed by several authors [19,20]. It is generally assumed that in the conducting state the polymer film resistance is considered as negligible compared to the electrolyte resistance. However, this resistance not alone contains the resistance of the polymer film but also the resistance of the electrolyte

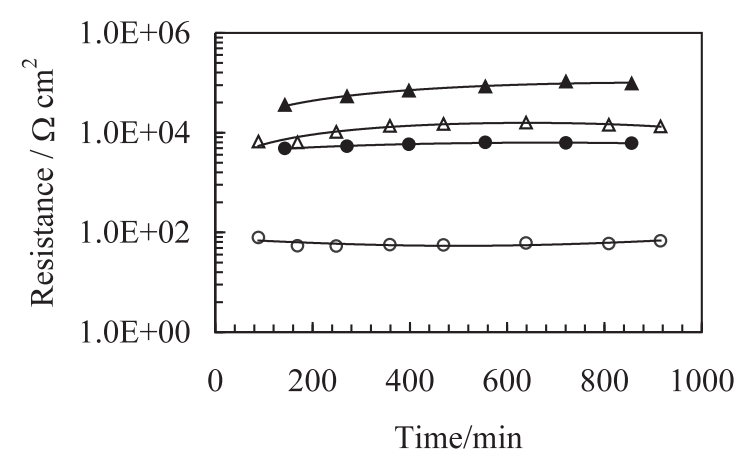

Fig. 10. Resistance elements plotted as a function of time for uncoated copper $\left(\bullet R_{1}, \boldsymbol{\Delta} R_{2}\right)$ and polypyrrole-coated copper $\left(\bigcirc R_{1}, \square R_{2}\right)$. 
contained within the porous polymer film. It is well documented that at the beginning of the polymer deposition process a very compact and dense polymer, of 150-200 nm in thickness, is formed. However with subsequent polymer chain growth, as in this study, loosely packed porous structures are produced [21,22].

However, this value of $60 \Omega \mathrm{cm}^{2}$ is somewhat higher than the resistance values reported for polymers in the conducting state, which suggests that these polypyrrole films deposited on the copper electrodes are somewhat oxidized. This is consistent with the fact that relatively high applied potentials, $900 \mathrm{mV}$ (SCE), are used in the electropolymerization procedure. The $Q_{1}$ term, which can be associated with the charging capacitance of the polypyrrole, adopts values in the region of $200 \mu \mathrm{F}$ $\mathrm{cm}^{-2}$. The $R_{2}$ term is also plotted as a function of time in Fig. 10. Again, this resistance term remains relatively constant independent of time, and although reaching high values, is significantly lower than the corresponding $R_{2}$ term for the uncoated electrode. This resistance term appears to be related to the conducting polypyrrole-copper interface. Possibly, the most significant aspect of these impedance data is the stability of the impedance response, which in turn indicates that the polymer-copper composite is stable in these highly aggressive solutions.

\section{Discussion}

It can be seen from the results presented that adherent and homogenous polypyrrole coatings can be deposited onto $\mathrm{Cu}$ in the presence of oxalate anions at near neutral $\mathrm{pH}$ values. These layers exhibit significant corrosion protection properties in highly aggressive chloride-containing solutions for considerable periods of time, exceeding 8 days of immersion.

The formation of polypyrrole at the copper surface appears to be associated with the passivation of the copper surface by an oxalate layer. All attempts to electropolymerize pyrrole, from an acid solution or a neutral sulphate or nitrate solution, failed because the copper electrode remained active in these media. However, this oxalate layer appears to be sufficiently protective to decrease the rate of copper dissolution, but also not sufficiently insulating to inhibit the electropolymerization process. A similar process has been reported for the formation of polyaniline at iron or iron-based electrodes [23,24]. For example, the electrosynthesis of adherent polyaniline films on iron has been reported in oxalic and phosphoric acid media and has been attributed to the formation of stable iron oxalate and phosphate complexes at the iron surface that facilitate the electropolymerization process. The formation of these copper oxalate species can be seen clearly in Figs. 1, 2 and 5(b), where the anodic peaks at potentials higher than $250 \mathrm{mV}$ (SCE) can be attributed to the formation of these species. It is well known that oxalate anions form stable complexes with copper cations. In particular, oxalate anions $\left(\mathrm{Ox}^{2-}\right)$ form complexes with $\mathrm{Cu}^{2+}$ to generate copper oxalate complexes with a $1: 1$ and 1:2 stoichiometry.

$$
\begin{aligned}
& \mathrm{Cu}^{2+}+\mathrm{Ox}^{2-} \rightleftharpoons \mathrm{Cu}(\mathrm{Ox}) \\
& \mathrm{Cu}^{2+}+2 \mathrm{Ox}^{2-} \rightleftharpoons\left(\mathrm{Cu}(\mathrm{Ox})_{2}\right)^{2-}
\end{aligned}
$$

The current peaks observed near 360 and 490 $\mathrm{mV}(\mathrm{SCE})$, first cycle in Fig. 1, appear to be connected with the 1:1 and 1:2 copper oxalate complexes respectively. These oxalate layers are relatively stable and offer some level of corrosion protection to the underlying copper substrate. For example, the ennoblement of the potentials at which the oxidation of copper to generate these complexes, Fig. 5(b), occurs, with repetitive cycling, is consistent with the protective qualities of the copper oxalate species. However, it is also evident from Fig. 5(b), that if the electrodes are subjected to high potentials in the region of $1000 \mathrm{mV}(\mathrm{SCE})$, then the copper oxalate species loose their protective properties, and thus are unable to protect the substrate, as evident from the reverse scans where high anodic currents are seen. Zouaoui et al [17] have shown clearly that $\left(\mathrm{Cu}(\mathrm{Ox})_{2}\right)^{2-}$ is the more stable complex in the $\mathrm{pH}$ range 3.0 to 11.0 for a solution of $\mathrm{Cu}^{2+}$ and $\mathrm{Ox}^{2-}$. Thus, this $\mathrm{Cu}$ oxalate layer is likely to contain copper as the $\left(\mathrm{Cu}(\mathrm{Ox})_{2}\right)^{2-}$ species.

There are also reports in the literature which show that the presence of dissolved $\mathrm{Cu}^{2+}$ increases the polymer yield during the synthesis of conducting polymers, such as polypyrrole $[25,26]$. For example, Millar et al. [25] in studying the reaction of pyrrole and thiophene monomers with copper- or nickel-exchanged mordenite found that polymerization occurred only with the copper-exchanged mordenite. This was attributed to the better oxidizing power of the $\mathrm{Cu}(\mathrm{II})$ cation. Thus, the presence of dissolved $\mathrm{Cu}^{2+}$ at the $\mathrm{Cu}$ electrode may also be connected with the ease of electropolymerization at the $\mathrm{Cu}$ electrode and the generation of a homogenous crack-free coating, as evident from the SEM micrograph shown in Fig. 4(a).

The corrosion-protection properties of the deposited polypyrrole can be seen in Figs. 6-10. There is clear evidence from these data that the polypyrrole-coated electrodes exhibit significant corrosion protection properties in both acidified and neutral chloride-containing solutions, particularly following formation. There is a clear ennoblement in the open-circuit potentials, as shown in Fig. 7. This effect, which is generally associated with an anodic protection mechanism, has also been reported for polyaniline-coated iron electrodes [23]. For this iron system the corrosion-protection properties are often gauged by measuring the period 
elapsed until the open-circuit potential of the polymercoated electrode drops to that of the uncoated electrode. This signifies loss of corrosion protection and typically lasts from minutes to hours. However with the polymer-copper system, the open-circuit potentials reach a steady-state value that is always more noble than the potential of the bare electrode, and even after 8 days of immersion remains at this steady-state value. Furthermore, the polymers remain protective even on polarization to relatively high potentials, as shown in Fig. 8. In particular, the data recorded following 8 days of immersion, show that the polymer remains stable and protective. This high level of stability can also be seen from the impedance data, Fig. 10, where the resistance parameters, $R_{1}$ and $R_{2}$, remain stable for periods exceeding $1000 \mathrm{~min}$, showing that the polymer is stable for extended periods. It can also be seen from these data that the polymer remains conducting during the 1000min period. This apparent stability of the polypyrrole layer on the copper electrode may be connected with recent reports which show that $\mathrm{Cu}(\mathrm{I})$ can be used to enhance the conductivity and stability of polypyrrole [26]. This has been attributed to electron transfer between copper and the $\mathrm{N}^{+}$of polypyrrole to form a stable $\mathrm{Cu}$-polypyrrole complex, thus preventing nucleophilic attack on the positively charged nitrogen.

\section{Conclusions}

Pyrrole was successfully electropolymerized at a copper electrode in a near neutral sodium oxalate solution to generate a homogeneous and adherent polypyrrole film. The electropolymerization process was facilitated by the formation of a stable copper oxalate layer, which inhibited dissolution of the copper electrode and was sufficiently conducting to enable the polymerization process. These films remained stable and conducting for periods exceeding 8 days and exhibited significant corrosion protection properties in acidified and neutral $0.1 \mathrm{~mol} \mathrm{dm}^{-3} \mathrm{NaCl}$ solutions.

\section{Acknowledgements}

The authors gratefully acknowledge the support of this work by Enterprise Ireland, under the Basic Science
Research Grants Award, Project Code SC/99/106 and Wexford County Council. The authors would also like to acknowledge the Biomedical Research Centre at NUI Galway for carrying out the SEM measurements.

\section{References}

[1] V. Brusic, M.A. Frisch, B.N. Eldridge, F.P. Novak, F.B. Kaufman, B.M. Rusch, G.S. Frankel, J. Electrochem. Soc. 138 (1991) 2253.

[2] C. Tornkvist, D. Thierry, J. Bergman, B. Liedberg, C. Leygraf, J. Electrochem. Soc. 136 (1989) 58.

[3] J.J. Kester, T.E. Furtak, A.J. Bevolo, J. Electrochem. Soc. 129 (1982) 1716

[4] A.M. Fenelon, C.B. Breslin, J. Appl. Electrochem. 31 (2001) 509.

[5] G.P. Cicileo, B.M. Rosales, F.E. Varela, J.R. Vilche, Corros. Sci. 41 (1999) 1359.

[6] A. Guenbour, A. Kacemi, A. Benbachir, Prog. Org. Coat. 39 (2000) 151.

[7] B. Trachli, M. Keddam, H. Takenouti, A. Srhiri, Corros. Sci. 44 (2002) 997.

[8] S. Kerit, J. Aride, A. Srhiri, A. Ben Bachir, K. Elkacemi, M. Etman, J. Appl. Electrochem. 23 (1993) 835.

[9] D. Taneichi, R. Haneda, K. Aramaki, Corros. Sci. 43 (2001) 1589.

[10] R. Haneda, K. Aramaki, J. Electrochem. Soc. 145 (1856) 1998.

[11] R. Haneda, K. Aramaki, J. Electrochem. Soc. 145 (1998) 2786.

[12] F.X. Perrin, J. Pagetti, Corros. Sci. 40 (1998) 1647.

[13] J.L. Camalet, J.C. Lacroix, S. Aeiyach, P.C. Lacaze, J. Electroanal. Chem. 445 (1998) 117.

[14] B.D. Sazou, C. Georgolios, J. Electroanal. Chem. 429 (1997) 81.

[15] J. He, V.J. Gelling, D.E. Tallman, G.P. Bierwagen, C.G. Wallace, J. Electrochem. Soc. 147 (2000) 3667.

[16] V. Brusic, M. Angelopoulos, T. Graham, J. Electrochem. Soc. 144 (1997) 436.

[17] A. Zouaoui, O. Stephan, M. Carrier, J.-C. Moutet, J. Electroanal. Chem. 474 (1999) 113.

[18] H. Nguyen, T. Le, B. Garcia, C. Delouis, Q. Le Xuan, Electrochim. Acta 46 (2001) 4259.

[19] E.S. Matveeva, M.J. Gonzalez-Tejera, J. Electrochem. Soc. 147 (2000) 1213.

[20] E. Musiani, Electrochim. Acta 35 (1990) 1665.

[21] C.M. Carlin, L.J. Kepley, A.J. Bard, J. Electrochem. Soc. 132 (1985) 358.

[22] K. Roßberg, G. Paasch, L. Dunsch, S. Ludwig, J. Electroanal. Chem. 443 (1998) 49.

[23] M.C. Bernard, S. Joiret, A. Hugot-Le-Goff, P.V. Phong, J. Electrochem. Soc. 148 (2001) B12.

[24] J.L. Camalet, J.C. Lacroix, S. Aeiyach, K. Chane-Ching, P.C. Lacaze, Synth. Met. 93 (1998) 133.

[25] G.J. Millar, G.F. McCann, C.M. Hobbis, G.A. Bowmaker, R.P. Conney, J. Chem. Soc. Faraday Trans. 90 (1994) 2579.

[26] B.L. Rivas, C.O. Sanchez, J. Appl. Poly. Sci. 82 (2001) 330. 